\title{
Emergence of Highly Multidrug-Resistant Bacteria Isolated from Patients with Infections Admitted to Public Hospitals in Southwest Iran
}

\author{
Sepide Namdari $\mathbb{D}^{1,2}$ Ali Farhadi $\mathbb{D D}^{1},{ }^{1}$ Aida Khademalhoseini $\left(\mathbb{D},{ }^{1}\right.$ \\ Abbas Behzad-Behbahani $\mathbb{D D}^{1}{ }^{1}$ and Afsaneh Moaddeb $\mathbb{D D}^{3}$ \\ ${ }^{1}$ Diagnostic Laboratory Sciences and Technology Research Center, School of Paramedical Sciences, \\ Shiraz University of Medical Sciences, Shiraz, Iran \\ ${ }^{2}$ Qaem Hospital, Firuzabad, Fars, Iran \\ ${ }^{3}$ Department of Bacteriology and Virology, School of Medicine, Shiraz University of Medical Sciences, Shiraz, Iran
}

Correspondence should be addressed to Afsaneh Moaddeb; moaddeba@sums.ac.ir

Received 6 April 2021; Accepted 29 July 2021; Published 13 August 2021

Academic Editor: Mary E. Marquart

Copyright $\odot 2021$ Sepide Namdari et al. This is an open access article distributed under the Creative Commons Attribution License, which permits unrestricted use, distribution, and reproduction in any medium, provided the original work is properly cited.

Background. The emergence of multidrug-resistant (MDR) microorganisms causing infections is increasing worldwide and becoming more serious in developing countries. Among those, Acinetobacter species are becoming prominent. Objectives. The aim of this study was to determine the rate of antimicrobial resistance of the bacteria causing infections, Acinetobacter species in particular, in local public hospitals in Firuzabad, Fars province, Iran. Methods. This cross-sectional study was performed on different clinical specimens collected from patients who were suspected of infections hospitalized from March 2016 to March 2019 in local hospitals of Firuzabad, Fars province, Iran. The bacterial isolates were identified following standard microbiological methods. Clinical and Laboratory Standards Institute guidelines were used to identify the antibiotic susceptibility of these isolates. Results. Overall, 1778 bacterial etiologies were isolated from 1533 patients diagnosed with infection. Of these, 1401 (78.8\%) were Gram-negative and the remaining were Gram-positive bacteria. Escherichia coli (37.1\%), Klebsiella spp. (13.9\%), and Acinetobacter species (10.4\%) were the most common isolated bacteria. Antibiotic sensitivity testing in this study showed a high resistance rate of Acinetobacter species to all antibiotics tested except Colistin. During the study period, the rate of infection with highly multidrug-resistant Acinetobacter species increased from $7.2 \%$ to $13.3 \%$. Conclusions. This study highlights the emergence of MDR bacterial agents such as Acinetobacter species as a new threat in our region. However, a decrease in the rate of infection with Pseudomonas aeruginosa was noticeable.

\section{Introduction}

The emergence of antimicrobial-resistant bacteria in the community and hospitals is a critical threat to public health worldwide [1-3]. Unnecessary antibiotic use, excessive use of broad-spectrum antibiotics, and improper prescription of antibiotic drugs are the main reasons for the increased prevalence of antibiotic-resistant microorganisms [4]. Despite this rise in the prevalence of drug-resistant pathogens, the development of new antimicrobial agents is declining drastically [5]. Accordingly, the possibility of facing a rising number of potentially untreatable infections in the near future is a cause for concern. Furthermore, decreased sensitivity to the available antibiotics is a major concern in Iranian healthcare facilities [6-8].

A major challenge in treating patients with bacterial infections is the selection of appropriate antibiotics for their treatment. This can be obtained based on the information on the antimicrobial resistance patterns in the area. For this reason, updated data on antimicrobial resistance patterns in every region is required.

The goal of the present study was to provide up-to-date data on the antibiotic resistance patterns of bacterial infections in this area. Such data could provide a practical 
guide for physicians. More importantly, it would highlight the serious threat of multidrug-resistant (MDR) bacteria causing infections, some of which are entirely resistant to every antibiotic available. Studies like this will draw special attention to the necessity of future studies in order to find new medications for treating infections with such bacteria.

\section{Methods}

2.1. Study Subjects. This cross-sectional study was conducted within a 3-year period from March 2016 to March 2019 in local public hospitals in Firuzabad, southwest Iran. The samples were taken as a part of the routine diagnostic practice; however, after the approval of the ethics committee (Approval ID: IR.SUMS.REC.1393.8313), informed consent was obtained from each participant or legal guardian.

Using sterile equipment and aseptic techniques, 1778 clinical samples including blood, urine, sputum, wound swab, and endotracheal tube specimens (ETT) were collected from 1533 patients diagnosed with infection based on clinical signs and laboratory investigations. Patients were aged between 1 and 90 years old $(38.7 \pm 24.4$ years $)$. The specimens were taken from patients by medical nurses and laboratory technicians and were transported to the laboratory immediately for further analysis.

2.2. Sample Collection. For blood culture collection, the venipuncture method was used to obtain blood samples. Two sets of blood specimens were collected from different venipuncture sites. Each bottle consisted of $7-10 \mathrm{~mL}$ of blood for adult patients [9]. The collected volume of blood for pediatric patients was based on the weight of the patients [10].

For the diagnosis of urinary tract infections (UTI), cleancatch midstream urine (MSU), neonatal bagged urine, indwelling catheter (Foley catheter) urine, or suprapubic catheter urine was collected from patients.

The sputum samples were taken into sterile containers and were immediately analyzed microscopically by Gram staining. The samples containing less than 10 epithelial cells and more than 25 leukocytes in each area upon $100 \mathrm{x}$ magnification were included in the study as eligible sputum specimens [11].

ETTs were obtained immediately after extubation. Roughly, $1 \mathrm{~cm}$ of the distal end of the ETTs was cut for microbiological culture analysis. The tips were placed in a 15 $\mathrm{mL}$ conical tube containing $5 \mathrm{~mL}$ of sterile phosphatebuffered saline (PBS). Conical tubes were centrifuged at $400 \mathrm{~g}$ upon delivery, and pellets were used for further analysis.

For wound culture, wounds were first rinsed thoroughly with sterile saline solution. A small area $(1 \mathrm{~cm})$ of clean viable tissue was identified, and the sterile swab was rotated on it for 5 seconds while applying enough pressure to produce exudate. Swabs were then transferred into sterile containers. All the specimens were processed in the laboratory immediately (within 1 hour) to keep the samples stable.
2.3. Bacteriological Investigation. Culturing and identification of isolates were on the basis of standard guidelines for microbiological examination $[12,13]$. Briefly, blood samples were collected as soon as the onset of clinical symptoms before administration of antimicrobial therapy. For the identification of pathogens, BACTEC ${ }^{\mathrm{TM}}$ (Becton Dickinson, USA) blood culture bottle system was employed. Blood culture specimens were incubated for 7 days. Positive blood cultures were plated on Columbia blood agar with 5\% sheep blood, MacConkey agar, and chocolate agar. Blood and MacConkey agar plates were incubated for 2 days in an atmosphere with $5 \% \mathrm{CO}_{2}$. Chocolate agar plates were incubated anaerobically in Gas-pack anaerobic jars with GasPack envelopes (BBL; Becton Dickinson \& Co., Cockeysville, Md., USA) and palladium catalyst to achieve and maintain an anaerobic atmosphere enriched with $\mathrm{CO} 2$.

Urine specimens were cultured on blood agar and MacConkey agar plates using calibrated $0.001 \mathrm{~mL}$ loops for quantitative urine cultures. Greater than or equal to 100000 colony-forming units (CFU) of bacteria per $\mathrm{mL}$ of MSU or neonatal bagged urine samples were considered positive for infection. A positive growth of bacteria for other types of urine specimens was considered infection as well.

Respiratory specimens were routinely cultured onto several solid media, including chocolate agar, sheep blood agar, and MacConkey agar. Sputum cultures with more than 5 colonies per plate of potential respiratory pathogens were considered positive for infection.

The assessment of wound infection was performed by inoculating the swabs on blood agar, MacConkey agar, and chocolate agar and incubating at $37^{\circ} \mathrm{C}$ for 24 to 48 hours.

All culture media were supplied from bioMérieux, France. Bacterial isolates were identified using conventional methods based on their morphological, biochemical, and physiological characteristics. Briefly, Gram staining was performed on smears of inoculums of single colonies from pure subcultures in $20 \mu \mathrm{l}$ of sterile PBS. The stained slides were analyzed using light microscopy. Subsequently, the identification of the isolated Gram-positive and Gramnegative bacteria was carried out using biochemical tests. For the Gram-positive isolates, catalase, coagulase, DNase, Bacitracin, Novobiocin and Optochin susceptibility, hippurate hydrolysis, $6.5 \% \mathrm{NaCl}$ broth salt tolerance, and bile esculin tests were applied. The identification of Gramnegative bacteria involved performing triple sugar iron (TSI), Simmon's citrate, sulfide-indole-motility (SIM), urease, methyl red (MR), Voges-Proskauer (VP), lysine decarboxylase, arginine decarboxylase, ornithine decarboxylase, phenylalanine deaminase, oxidase, oxidation-fermentation (OF), and acetate utilization tests [14].

2.4. Antibiotic Susceptibility Testing. The antimicrobial susceptibility test (AST) was performed for all isolates using the standard Kirby-Bauer disk diffusion method [15]. The antibiotics for disc diffusion testing for both Gram-positive and Gram-negative isolates were in the following concentrations: Ceftizoxime $(30 \mu \mathrm{g})$, Amikacin $(30 \mu \mathrm{g})$, Cefixime $(5 \mu \mathrm{g})$, Ciprofloxacin $(5 \mu \mathrm{g})$, Nitrofurantoin $(200 \mu \mathrm{g})$, 
Gentamicin $(10 \mu \mathrm{g})$, Nalidixic acid $(30 \mu \mathrm{g})$, Ceftriaxone $(30 \mu \mathrm{g})$, Co-Trimoxazole $(25 \mu \mathrm{g})$, Norfloxacin $(10 \mu \mathrm{g})$, Tetracycline $(30 \mu \mathrm{g})$, Chloramphenicol $(30 \mu \mathrm{g})$, and Imipenem $(10 \mu \mathrm{g})$. In case of some Gram-positive isolates, Vancomycin $(30 \mu \mathrm{g})$, Ampicillin $(10 \mu \mathrm{g})$, Clindamycin $(2 \mu \mathrm{g})$, and Erythromycin $(15 \mu \mathrm{g})$ were also used. Colistin in a concentration of $10 \mu \mathrm{g}$ was used for MDR pathogens such as Acinetobacter spp., Pseudomonas aeruginosa, and Klebsiella pneumoniae. MDR was defined as resistance to at least one antibiotic in at least three antimicrobial categories [16].

Antimicrobial discs were obtained from Padtan-TEB Co., Tehran, Iran. For the interpretation of antibiotic susceptibility testing, diameters of inhibition zones around the discs were measured and were classified as sensitive (S), intermediate (I), and resistant (R) as suggested by Clinical and Laboratory Standards Institute (CLSI) (https://clsi.org).

The quality control strains used in the study were Escherichia coli (ATCC ${ }^{\circledR} 25922^{\mathrm{TM}}$ ), Pseudomonas aeruginosa (ATCC ${ }^{\circledR} 27853^{\mathrm{TM}}$ ), Staphylococcus aureus (ATCC ${ }^{\circledR} 25923^{\mathrm{TM}}$ ), and Enterococcus faecalis (ATCC ${ }^{\circledR} 29212^{\mathrm{TM}}$ ).

2.5. Statistical Analysis. Data management and analysis was carried out using WHONET 5.6 software.

\section{Results}

Overall, 1533 patients developed infections during this three-year study. Among them, 889 (58\%) were female and $644(42 \%)$ were male. Infections with Gram-positive and Gram-negative bacteria were detected in 293 out of 1533 (19.1\%) and in 1181 out of 1533 (77.0\%) patients, respectively. Furthermore, coinfection with both Gram-positive and Gram-negative bacteria was found in 59 out of 1533 patients (3.8\%). The distribution of bacterial isolates in different clinical specimens and hospital wards is shown in Tables 1 and 2, respectively.

Among Gram-negative bacteria, E. coli (37.1\%), Klebsiella spp. (13.9\%), and Acinetobacter spp. (10.4\%) were dominant causes of infections. However, S. aureus was the most prevalent isolate among Gram-positive bacteria (Figure 1).

The prevalence of bacteria involved in infections during the study period is presented in Table 3 . There was a decrease in the rate of Pseudomonas aeruginosa infections from $12.2 \%$ in the years 2016-2017 to $4.8 \%$ in the years 2018-2019. However, an increasing trend in infections due to Acinetobacter spp. from $7.2 \%$ in the years $2016-2017$ to $13.3 \%$ in the years 2018-2019 was demonstrated (Table 3). The antibiotic resistance patterns of the Gram-positive and Gramnegative bacteria are presented in Tables 4 and 5, respectively.

MDR patterns of Gram-positive and Gram-negative bacterial agents are shown in Tables 6 and 7 . The highest rate of multidrug resistance among Gram-positive bacteria was found in the isolates of Enterococcus spp. (91.4\%), followed by $S$. epidermidis (64.9\%) and S. aureus (38.8\%), while among Gram-negative bacteria, the highest rate of multidrug resistance was detected in the isolates of Acinetobacter spp.
(100\%), followed by Klebsiella spp. (58.5\%) and E. coli (54.0\%).

Urinary tract infection was present in $62.1 \%$ of the patients, followed by respiratory tract infection (19.6\%) and wound infection (15.5\%). UTIs were more frequent among women $(74 \%)$, and E. coli was the major cause of them (62.0\%).

About fifty-five percent of the patients with respiratory tract infections were those who were receiving tracheal intubation, most of whom were hospitalized in intensive care units (ICU). The main bacteria isolated from ETT cultures were Acinetobacter spp. (44.9\%). The same bacteria were the most frequent cause of positive sputum cultures (28.2\%). These bacteria were highly resistant to most of the antibiotics. However, Colistin was the only antibiotic that all of the mentioned bacteria were still sensitive to.

Staphylococcus epidermidis was the major cause of positive blood cultures (20.0\%) and these bacteria showed the most sensitivity to Vancomycin and were most resistant to Erythromycin. Furthermore, Staphylococcus aureus was the most frequent microorganism isolated from wound cultures (21.8\%), all of which were sensitive to Vancomycin.

\section{Discussion}

In the present study, the pattern of antibiotic resistance of bacteria isolated from patients with infection was investigated. During three years of study, 1533 patients developed infections. When the incidence of infections was examined in different wards of general hospitals in Firuzabad, Fars province, Iran, the patients admitted in the internal medicine ward, in particular, had the highest rate of infection (28.9\%) followed by surgical (orthopedic and general surgery) wards (23\%), the pediatric ward (13\%), neonatal ICU (12\%), ICU (11.5\%), CCU (7.4\%), and emergency department (4.2\%). UTI was the most frequent infection during the study period. Escherichia coli was found to be the most common pathogen isolated (37.1\%), followed by Klebsiella spp. (13.9\%) and Acinetobacter spp. (10.4\%).

Overall, the prevalence of infections with Gram-negative bacteria was higher than Gram-positive bacteria (78.8\% versus $21.2 \%)$. The most frequent Gram-negative bacteria causing infections were E. coli (21.6\%), while in other studies Enterobacter spp., Klebsiella pneumoniae, and Pseudomonas aeruginosa were the most prevalent causative organisms of infections [17], the incidence of infection with E. coli and Acinetobacter spp. is increasing in our region. The prevalence of MDR among Acinetobacter spp. isolates was found to be $100 \%$, which is far higher than reports from Saudi Arabia (74\%) and Ethiopia (71.6\%) $[18,19]$. The emergence of MDR Acinetobacter spp. may complicate the choice of the accurate antibiotic for treatment and increase the mortality rate in hospitalized patients [20]. Except for Colistin (Polymyxin E) with 100\% sensitivity, Acinetobacter spp. isolates exhibited high rates of resistance to all the antibiotics that are routinely used in clinical pathology laboratories for Gram-negative bacteria. These results contradict with a previous study in which drug resistance to Colistin was high $(49.8 \%)$ in the northern part of Iran [21]. 
TABLE 1: Distribution of bacteria isolated from different samples collected from patients with infections.

\begin{tabular}{|c|c|c|c|c|c|c|}
\hline \multirow[b]{2}{*}{ Microorganism } & \multicolumn{6}{|c|}{ Source of specimen } \\
\hline & Total & Urine & $\begin{array}{c}\text { Blood } \\
\text { Number }\end{array}$ & Wound & Sputum & ETT \\
\hline Acinetobacter spp. & 185 (10.4) & 0 & $9(6.9)$ & $19(8.0)$ & $82(28.2)$ & $75(44.9)$ \\
\hline Enterobacter spp. & $62(3.5)$ & $44(4.6)$ & $6(4.6)$ & $12(5.0)$ & 0 & 0 \\
\hline Enterococcus spp. & $117(6.6)$ & $77(8.1)$ & $12(9.2)$ & $28(11.8)$ & 0 & 0 \\
\hline Escherichia coli & $659(37.1)$ & $590(62.0)$ & $21(16.1)$ & $15(6.3)$ & $22(7.6)$ & $11(6.6)$ \\
\hline Klebsiella spp. & $248(13.9)$ & $154(16.2)$ & $13(10.0)$ & $27(11.3)$ & $34(11.7)$ & $20(12.0)$ \\
\hline Proteus spp. & $63(3.5)$ & $41(4.3)$ & $5(3.8)$ & $17(7.1)$ & 0 & 0 \\
\hline Pseudomonas aeruginosa & $142(8.0)$ & $29(3.0)$ & $8(6.1)$ & $39(16.4)$ & $35(12.0)$ & $31(18.6)$ \\
\hline Staphylococcus aureus & $134(7.5)$ & $17(1.8)$ & $12(9.2)$ & $52(21.8)$ & $34(11.7)$ & $19(11.4)$ \\
\hline Staphylococcus epidermidis & $77(4.3)$ & 0 & $26(20.0)$ & $29(12.2)$ & $11(3.8)$ & $11(6.6)$ \\
\hline Stenotrophomonas maltophilia & $24(1.3)$ & 0 & $11(8.5)$ & 0 & $13(4.5)$ & 0 \\
\hline Streptococcus pneumoniae & $49(2.7)$ & 0 & 0 & 0 & $49(16.8)$ & 0 \\
\hline Other nonfermentative bacteria & $18(1.0)$ & 0 & $7(5.4)$ & 0 & $11(3.8)$ & 0 \\
\hline Total & 1778 & 952 & 130 & 238 & 291 & 167 \\
\hline
\end{tabular}

ETT: endotracheal tube specimen.

TABLE 2: Distribution of bacteria isolated from patients with infections in different hospital wards.

\begin{tabular}{|c|c|c|c|c|c|c|c|}
\hline \multirow{3}{*}{ Microorganism } & \multicolumn{7}{|c|}{ Hospital ward } \\
\hline & Internal medicine & Surgical wards & Pediatric ward & NICU & ICU & $\mathrm{CCU}$ & $\begin{array}{l}\text { Emergency } \\
\text { department }\end{array}$ \\
\hline & \multicolumn{7}{|c|}{ Number of isolates (\%) } \\
\hline Acinetobacter spp. & $25(4.9)$ & $29(7.1)$ & $19(8.2)$ & $32(15.0)$ & $59(28.9)$ & $18(13.6)$ & $3(4.0)$ \\
\hline Enterobacter spp. & $18(3.5)$ & $16(3.9)$ & $5(2.2)$ & $2(0.9)$ & $6(2.9)$ & $12(9.1)$ & $3(4.0)$ \\
\hline Enterococcus spp. & $10(1.9)$ & $38(9.3)$ & $7(3.0)$ & $13(6.1)$ & $25(12.2)$ & $18(13.6)$ & $6(8.0)$ \\
\hline Escherichia coli & $265(51.6)$ & $168(41.1)$ & $105(45.4)$ & $49(23.0)$ & $30(14.7)$ & $13(9.8)$ & $29(38.7)$ \\
\hline Klebsiella spp. & $94(18.3)$ & $22(5.4)$ & $35(15.1)$ & $38(17.8)$ & $15(7.3)$ & $26(19.7)$ & $18(24)$ \\
\hline Proteus spp. & $19(3.7)$ & $18(4.4)$ & $4(1.7)$ & $7(3.3)$ & $5(2.4)$ & $6(4.5)$ & $4(5.3)$ \\
\hline Pseudomonas aeruginosa & $19(3.7)$ & $26(6.4)$ & $15(6.5)$ & $34(15.9)$ & $27(13.2)$ & $19(14.4)$ & $2(2.7)$ \\
\hline Staphylococcus aureus & $34(6.6)$ & $62(15.2)$ & $6(2.6)$ & $13(6.1)$ & $9(4.4)$ & $8(6.1)$ & $2(2.7)$ \\
\hline Staphylococcus epidermidis & $14(2.7)$ & $16(3.9)$ & $12(5.2)$ & $8(3.7)$ & $18(8.8)$ & $6(4.5)$ & $3(4.0)$ \\
\hline Stenotrophomonas maltophilia & $3(0.6)$ & $7(1.7)$ & $5(2.2)$ & $3(1.4)$ & $3(1.5)$ & $2(1.5)$ & $1(1.3)$ \\
\hline Streptococcus pneumoniae & $9(1.7)$ & 0 & $17(7.4)$ & $12(5.6)$ & $5(2.4)$ & $3(2.3)$ & $3(4.0)$ \\
\hline Other nonfermentative bacteria & $4(0.8)$ & $7(1.7)$ & $1(0.4)$ & $2(0.9)$ & $2(1.0)$ & $1(0.8)$ & $1(1.3)$ \\
\hline Total & 514 & 409 & 231 & 213 & 204 & 132 & 75 \\
\hline
\end{tabular}

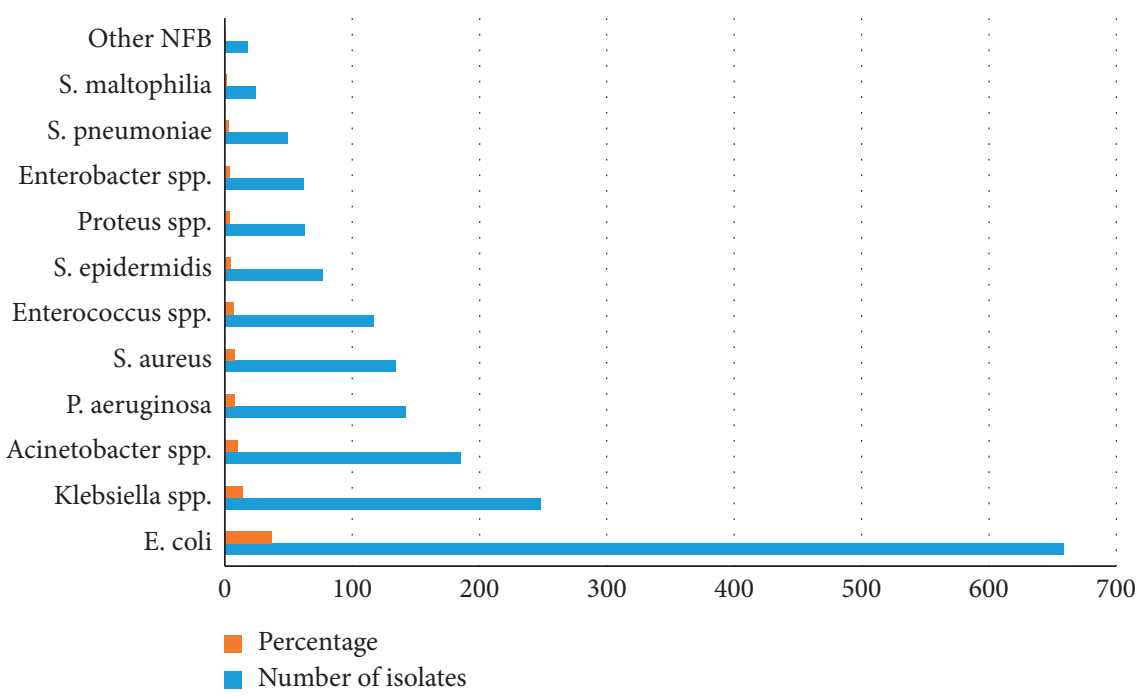

FIGURE 1: Frequency of bacteria isolated from clinical samples of patients with infections; NFB: nonfermentative bacteria. 
TABLE 3: Prevalence of bacterial infections during the three-year study period.

\begin{tabular}{|c|c|c|c|}
\hline \multirow[b]{2}{*}{ Microorganism } & \multicolumn{3}{|c|}{ Sample collection dates } \\
\hline & 2016-2017 & $\begin{array}{c}\text { 2017-2018 } \\
\text { Number of isolates (\%) }\end{array}$ & 2018-2019 \\
\hline Acinetobacter spp. & $39(7.2)$ & $58(10.0)$ & $88(13.3)$ \\
\hline Enterobacter spp. & $17(3.1)$ & $23(4.0)$ & $22(3.3)$ \\
\hline Enterococcus spp. & $43(8.0)$ & $39(6.7)$ & $35(5.3)$ \\
\hline Escherichia coli & $188(34.9)$ & $217(37.3)$ & $254(38.5)$ \\
\hline Klebsiella spp. & $69(12.8)$ & $83(14.3)$ & $96(14.6)$ \\
\hline Proteus spp. & $27(5.0)$ & $22(3.8)$ & $14(2.1)$ \\
\hline Pseudomonas aeruginosa & $66(12.2)$ & $44(7.6)$ & $32(4.8)$ \\
\hline Staphylococcus aureus & $45(8.4)$ & $44(7.6)$ & $45(6.8)$ \\
\hline Staphylococcus epidermidis & $23(4.3)$ & $19(3.3)$ & $35(5.3)$ \\
\hline Stenotrophomonas maltophilia & $5(0.9)$ & $10(1.7)$ & $9(1.4)$ \\
\hline Streptococcus pneumoniae & $12(2.2)$ & $15(2.6)$ & $22(3.3)$ \\
\hline Other nonfermentative bacteria & $4(0.7)$ & $7(1.2)$ & $7(1.1)$ \\
\hline Total & 538 & 581 & 659 \\
\hline
\end{tabular}

Table 4: Antibiotic resistance patterns of Gram-positive bacteria isolated from patients with infections.

\begin{tabular}{|c|c|c|c|c|c|c|c|c|c|c|c|c|}
\hline \multirow{2}{*}{ Antibiotics } & \multicolumn{3}{|c|}{ Enterococcus spp. } & \multicolumn{3}{|c|}{ S. aureus } & \multicolumn{3}{|c|}{ S. epidermidis } & \multicolumn{3}{|c|}{ S. pneumoniae } \\
\hline & $\mathrm{R} \%$ & $\mathrm{I} \%$ & S\% & $\mathrm{R} \%$ & $\mathrm{I} \%$ & S\% & $\mathrm{R} \%$ & $\mathrm{I} \%$ & $\mathrm{~S} \%$ & $\mathrm{R} \%$ & $\mathrm{I} \%$ & $\mathrm{~S} \%$ \\
\hline Amikacin & NA & NA & NA & 3.0 & 0 & 97.0 & 7.8 & 3.9 & 88.3 & NA & NA & NA \\
\hline Ciprofloxacin & 93.2 & 5.1 & 1.7 & 22.4 & 4.5 & 73.1 & 63.6 & 1.3 & 35.1 & NA & NA & NA \\
\hline Nitrofurantoin & 11.1 & 21.4 & 67.5 & 20.1 & 7.5 & 72.4 & 3.9 & 3.9 & 92.2 & NA & NA & NA \\
\hline Gentamicin & 84.6 & 8.5 & 6.8 & 14.2 & 0 & 85.8 & 28.6 & 5.2 & 66.2 & NA & NA & NA \\
\hline Ceftriaxone & NA & NA & NA & 30.6 & 5.2 & 64.2 & 71.4 & 11.7 & 16.9 & 42.9 & 4.1 & 53.1 \\
\hline SXT & NA & NA & NA & 20.1 & 3.0 & 76.9 & 58.4 & 1.3 & 40.2 & 32.6 & 4.1 & 63.3 \\
\hline Norfloxacin & 94 & 4.3 & 1.7 & 39.6 & 6.7 & 53.7 & 63.6 & 1.3 & 35.1 & NA & NA & NA \\
\hline Tetracycline & 92.3 & 0 & 7.7 & 42.5 & 0.7 & 56.7 & 64.9 & 0 & 35.1 & 51.0 & 6.1 & 42.9 \\
\hline Vancomycin & 75.2 & 17.9 & 6.8 & 0 & 0 & 100 & 1.3 & 0 & 98.7 & 0 & 0 & 100 \\
\hline Ampicillin & 60.7 & 4.3 & 35.0 & NA & NA & NA & NA & NA & NA & NA & NA & NA \\
\hline Chloramphenicol & 32.5 & 13.7 & 53.8 & 8.2 & 6.0 & 85.8 & 5.2 & 3.9 & 90.9 & 12.2 & 0 & 87.7 \\
\hline Clindamycin & NA & NA & NA & 33.6 & 4.5 & 61.9 & 71.4 & 2.6 & 26.0 & 28.6 & 2.0 & 69.4 \\
\hline Erythromycin & NA & NA & NA & 38.8 & 5.2 & 56.0 & 84.4 & 0 & 15.6 & 30.6 & 6.1 & 63.2 \\
\hline
\end{tabular}

R: resistant, I: intermediate, S: sensitive, SXT: Co-Trimoxazole, and NA: not applicable.

Furthermore, between $5.3 \%$ and $69.8 \%$ of isolated E. coli were resistant to different antibiotics. Among the tested antibiotics for $E$. coli isolates, the lowest antibiotic resistance was detected for Amikacin, followed by Colistin. However, these isolates were highly resistant to Nalidixic acid and Co-Trimoxazole, which is consistent with a previous report from Isfahan, Iran [22]. Pseudomonas aeruginosa isolates showed high rates of sensitivity to the studied antibiotics and were detected in only $8.0 \%$ of infections, which is far lower than infections with $E$. coli and Acinetobacter spp. isolated from clinical samples. The rate of MDR among Pseudomonas aeruginosa isolates was $9.8 \%$, which is lower than the MDR rate of $31 \%$ reported by a recent study in Tehran, Iran [23].

Staphylococcus aureus was the most common Grampositive bacteria isolated from infected patients and generally comprised $7.5 \%$ of all bacterial infections and $35.5 \%$ of all Gram-positive bacterial infections. Staphylococcus aureus was mostly isolated from patients with wound and respiratory tract infections. We did not find Vancomycin-resistant Staphylococcus aureus during the study period among infected patients. This finding is in line with that of a previous study on Staphylococcus aureus in which although all studied isolates were MDR, they were generally susceptible to Vancomycin [24].

Enterococcus spp., as the second most frequent isolated Gram-positive bacteria, showed a notably high multidrug resistance rate of $91.4 \%$, which is comparable to the rates reported by a study in Taiwan [25]. Further, 75.2\% of Enterococcus spp. isolates were found to be Vancomycin-resistant, which might be associated with the extensive use of Vancomycin in the hospital environment. Vancomycinresistant Enterococci (VRE) have become a serious problem in almost every hospital and especially in high-risk patients [26-28].

There were 116 patients with the same bacterial isolates from different clinical samples. All isolates were tested for their antibiotic susceptibility. Approximately $80 \%$ of them had the similar patterns of antibiotic susceptibility. However, 52 patients had different bacterial species in clinical samples collected from multiple anatomical sites of infection. 


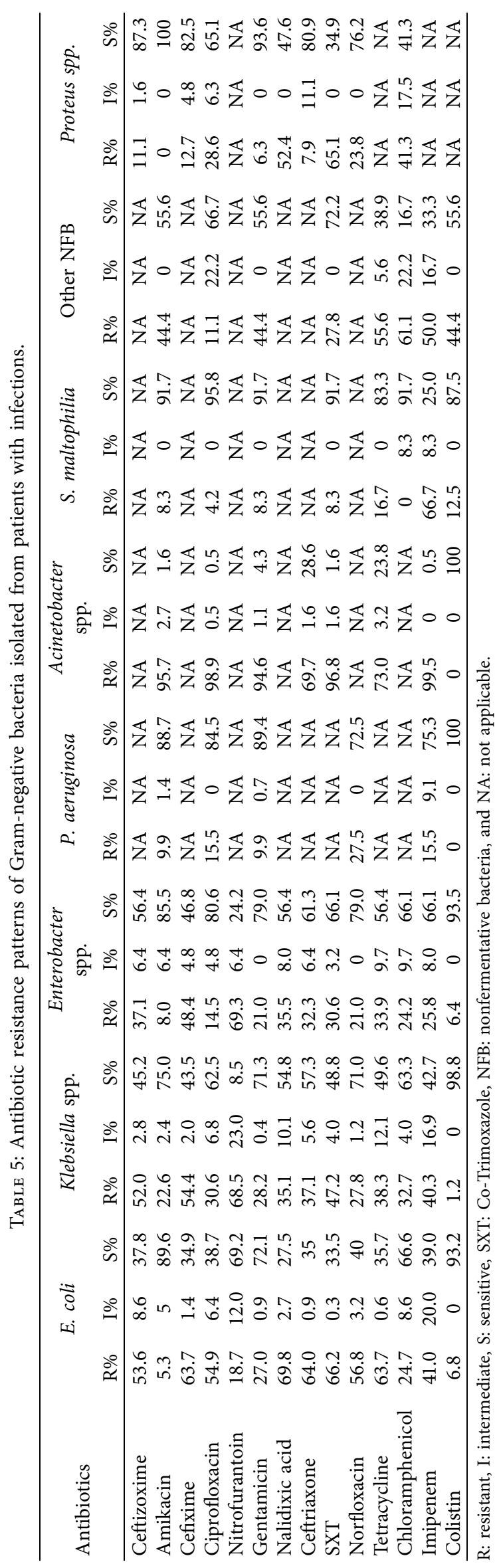


TABLe 6: Multidrug resistance patterns of Gram-positive bacteria isolated from patients with infections.

\begin{tabular}{|c|c|c|c|}
\hline Microorganism & Number of antibiotics & $\begin{array}{c}\text { Antibiotic resistant isolates } \\
\text { No (\%) }\end{array}$ & Multidrug resistance patterns \\
\hline \multirow{5}{*}{ Enterococcus spp. $(\mathrm{No}=117)$} & 5 & $48(41.0)$ & CIP, TE, GM, V, AMP \\
\hline & 4 & $26(22.2)$ & CIP, TE, GM, V \\
\hline & 4 & $19(16.2)$ & CIP, TE, GM, AMP \\
\hline & 3 & $6(5.1)$ & CIP, TE, GM \\
\hline & 3 & $8(6.8)$ & CIP, TE, V \\
\hline \multirow{7}{*}{ S. aureus $(\mathrm{No}=134)$} & 5 & $3(2.2)$ & CIP, GM, E, CC, SXT \\
\hline & 4 & $10(7.5)$ & CIP, E, CC, TE \\
\hline & 3 & $6(4.5)$ & E, SXT, CHL \\
\hline & 3 & $3(2.2)$ & $\mathrm{GM}, \mathrm{E}, \mathrm{CHL}$ \\
\hline & 3 & $13(9.7)$ & $\mathrm{E}, \mathrm{CC}, \mathrm{TE}$ \\
\hline & 3 & $8(6.0)$ & CIP, E, CC \\
\hline & 3 & $9(6.7)$ & CIP, GM, E \\
\hline \multirow{7}{*}{ S. epidermidis $(\mathrm{No}=77)$} & 5 & $5(6.5)$ & CIP, GM, E, CC, SXT \\
\hline & 4 & $6(7.8)$ & E, CC, TE, SXT \\
\hline & 4 & $5(6.5)$ & CIP, E, CC, TE \\
\hline & 3 & $2(2.6)$ & $\mathrm{GM}, \mathrm{E}, \mathrm{CHL}$ \\
\hline & 3 & $8(10.4)$ & $\mathrm{E}, \mathrm{CC}, \mathrm{TE}$ \\
\hline & 3 & $11(14.3)$ & CIP, E, CC \\
\hline & 3 & $13(16.9)$ & E, TE, SXT \\
\hline \multirow{2}{*}{ S. pneumoniae $(\mathrm{No}=49)$} & 4 & $3(6.1)$ & E, CC, TE, SXT \\
\hline & 3 & $5(10.2)$ & E, CC, TE \\
\hline
\end{tabular}

CIP: Ciprofloxacin, TE: Tetracycline, GM: Gentamicin, V: Vancomycin, AMP: Ampicillin, E: Erythromycin, CC: Clindamycin, SXT: Co-Trimoxazole, and CHL: Chloramphenicol.

TABLE 7: Multidrug resistance patterns of Gram-negative bacteria isolated from patients with infections.

\begin{tabular}{|c|c|c|c|}
\hline Microorganism & Number of antibiotics & $\begin{array}{c}\text { Antibiotic resistant isolates } \\
\text { No }(\%)\end{array}$ & Multidrug resistance patterns \\
\hline \multirow{7}{*}{ Escherichia coli $(\mathrm{No}=659)$} & 6 & $45(6.8)$ & SXT, TE, IMP, GM, CHL, COL \\
\hline & 5 & $35(5.3)$ & SXT, CRO, CIP, GM, AMK \\
\hline & 4 & $58(8.8)$ & SXT, TE, CIP, GM \\
\hline & 4 & $36(5.5)$ & SXT, TE, CHL, CIP \\
\hline & 3 & $62(9.4)$ & SXT, TE, CHL \\
\hline & 3 & $66(10)$ & SXT, TE, IMP \\
\hline & 3 & $54(8.2)$ & SXT, CRO, CIP \\
\hline \multirow{5}{*}{ Klebsiella spp. $(\mathrm{No}=248)$} & 5 & $3(1.2)$ & SXT. TE, CIP, GM, COL \\
\hline & 4 & $47(18.9)$ & CRO, CIP, GM, AMK \\
\hline & 3 & $33(13.3)$ & SXT, TE, IMP \\
\hline & 3 & $36(14.5)$ & SXT, TE, CHL \\
\hline & 3 & $26(10.5)$ & SXT, CRO, CIP \\
\hline \multirow{4}{*}{ Enterobacter spp. $(\mathrm{No}=62)$} & 4 & $4(6.4)$ & CRO, CIP, GM, AMK \\
\hline & 3 & $6(9.7)$ & SXT, TE, CRO \\
\hline & 3 & $7(11.3)$ & SXT, TE, IMP \\
\hline & 3 & $6(9.7)$ & SXT, TE, CHL \\
\hline$P$. aeruginosa $(\mathrm{No}=142)$ & 4 & $14(9.9)$ & IMP, CIP, GM, AMK \\
\hline \multirow{8}{*}{ Acinetobacter spp. $(\mathrm{No}=185)$} & 7 & $129(69.7)$ & SXT, TE, IMP, CRO, CIP, GM, AMK \\
\hline & 6 & $6(3.2)$ & SXT, TE, IMP, CIP, GM, AMK \\
\hline & 5 & $31(16.7)$ & SXT, IMP, CIP, GM, AMK \\
\hline & 4 & $6(3.2)$ & IMP, CIP, GM, AMK \\
\hline & 4 & $2(1.1)$ & SXT, IMP, GM, AMK \\
\hline & 4 & $1(0.5)$ & SXT, CIP, GM, AMK \\
\hline & 4 & $2(1.1)$ & SXT, IMP, CIP, AMK \\
\hline & 3 & $8(4.3)$ & SXT, IMP, CIP \\
\hline Proteus spp. $(\mathrm{No}=63)$ & 3 & $5(7.9)$ & SXT, CHL, CIP \\
\hline
\end{tabular}

SXT: Co-Trimoxazole, TE: Tetracycline, IMP: Imipenem, GM: Gentamicin, CHL: Chloramphenicol, COL: Colistin, CRO: Ceftriaxone, CIP: Ciprofloxacin, and AMK: Amikacin. 


\section{Conclusion}

In conclusion, the results indicate the increasing prevalence of infections with emerging opportunistic pathogens such as Acinetobacter spp. in our region. They are able to cause different types of infections. While the rate of infection with other Gram-positive and Gram-negative bacteria remains unchanged during the study period, a reduction in the rate of infection with Pseudomonas aeruginosa is evident. However, the emergence of MDR Acinetobacter spp. seems to become a major threat in the near future. Further, the considerable rate of infection with $E$. coli should not be ignored. Moreover, the molecular analysis of the isolates is recommended to characterize the antibiotic resistance genes.

\section{Data Availability}

Data are available within the article.

\section{Disclosure}

The funder had no role in the study design, data collection and analysis, decision to publish, or preparation of the manuscript.

\section{Conflicts of Interest}

The authors declare that they have no conflicts of interest.

\section{Acknowledgments}

This research work was conducted as part of the project no. 93-01-45-8313, supported by Shiraz University of Medical Sciences. The authors would like to thank the director and all the staff of medical laboratories in local public hospitals in Firuzabad, Fars province, Iran, for their cooperation in this study.

\section{References}

[1] I. Roca, M. Akova, F. Baquero et al., "The global threat of antimicrobial resistance: science for intervention," New Microbes and New Infections, vol. 6, pp. 22-29, 2015.

[2] R. Lawton, "Intensive care antimicrobial resistance epidemiology (ICARE) surveillance report, data summary from January 1996 through December 1997," American Journal of Infection Control, vol. 27, no. 3, pp. 279-284, 1999.

[3] J. S. Bradley, R. Guidos, S. Baragona et al., "Anti-infective research and development-problems, challenges, and solutions," The Lancet Infectious Diseases, vol. 7, no. 1, pp. 68-78, 2007.

[4] I. N. Okeke, A. Lamikanra, and R. Edelman, "Socioeconomic and behavioral factors leading to acquired bacterial resistance to antibiotics in developing countries," Emerging Infectious Diseases, vol. 5, no. 1, pp. 18-27, 1999.

[5] B. Spellberg, R. Guidos, D. Gilbert et al., "The epidemic of antibiotic-resistant infections: a call to action for the medical community from the Infectious Diseases Society of America," Clinical Infectious Diseases, vol. 46, no. 2, pp. 155-164, 2008.

[6] A. Jahansepas, M. Aghazadeh, M. A. Rezaee et al., "Occurrence of Enterococcus faecalis and Enterococcus faeciumin various clinical infections: detection of their drug resistance and virulence determinants," Microbial Drug Resistance, vol. 24, no. 1, pp. 76-82, 2018.

[7] H. Razavi Nikoo, A. Ardebili, and J. Mardaneh, "Systematic review of antimicrobial resistance of ClinicalAcinetobacter baumanniiIsolates in Iran: an update," Microbial Drug Resistance, vol. 23, no. 6, pp. 744-756, 2017.

[8] B. Poorabbas, J. Mardaneh, Z. Rezaei et al., "Nosocomial Infections: multicenter surveillance of antimicrobial resistance profile of Staphylococcus aureus and Gram negative rods isolated from blood and other sterile body fluids in Iran," Iranian Journal of Microbiology, vol. 7, no. 3, pp. 127-35, 2015.

[9] T. J. Kirn and M. P. Weinstein, "Update on blood cultures: how to obtain, process, report, and interpret," Clinical Microbiology and Infection, vol. 19, no. 6, pp. 513-520, 2013.

[10] J. A. Kellogg, J. P. Manzella, and D. A. Bankert, "Frequency of low-level bacteremia in children from birth to fifteen years of age," Journal of Clinical Microbiology, vol. 38, no. 6, pp. 2181-2185, 2000.

[11] O. Aydemir, Y. Aydemir, and M. Ozdemir, "The role of multiplex PCR test in identification of bacterial pathogens in lower respiratory tract infections," Pakistan Journal of Medical Sciences, vol. 30, no. 5, pp. 1011-6, 2014.

[12] W. Winn, "Introduction to microbiology part II: guidelines for the collection, transport, processing, analysis and reporting of cultures from specific specimen sources," Koneman's Color Atlas and Textbook of Diagnostic Microbiology, pp. 67-105, Lippincott William \& Wilkins, Philadelpia, Pennsylvania, 2006.

[13] J. G. Collee, R. Miles, and B. Watt, "Tests for identification of bacteria," Mackie and McCartney Practical Medical Microbiology, vol. 14, pp. 131-149, 1996.

[14] J. G. Holt, N. R. Krieg, and P. H. Sneath, Bergey's Manual of Determinative Bacterology, Wiley, New York, NY, USA, 2013.

[15] P. Wayne, Performance Standards for Antimicrobial Susceptibility Testing, Clinical and Laboratory Standards Institute, Wayne, PA, USA, 2011.

[16] A.-P. Magiorakos, A. Srinivasan, R. B. Carey et al., "Multidrug-resistant, extensively drug-resistant and pandrug-resistant bacteria: an international expert proposal for interim standard definitions for acquired resistance," Clinical Microbiology and Infection, vol. 18, no. 3, pp. 268-281, 2012.

[17] C. Elliott and A. Justiz-Vaillant, "Nosocomial infections: a 360-degree review," International Biological and Biomedical Journal, vol. 4, no. 2, pp. 72-81, 2018.

[18] M. K. Almaghrabi, "Multidrug-resistant Acinetobacter baumannii: an emerging health threat in aseer region, Kingdom of Saudi Arabia," Canadian Journal of Infectious Diseases and Medical Microbiology, vol. 2018, Article ID 9182747, 4 pages, 2018.

[19] Z. Ayenew, E. Tigabu, E. Syoum, S. Ebrahim, D. Assefa, and E. Tsige, "Multidrug resistance pattern of Acinetobacter species isolated from clinical specimens referred to the Ethiopian Public Health Institute: 2014 to 2018 trend anaylsis," PLoS One, vol. 16, no. 4, Article ID e0250896, 2021.

[20] Y. Gorbich, I. Karpov, and O. Kretchikova, "Impact of appropriate antimicrobial therapy on survival in patients with Acinetobacter baumannii-associated infections," Journal of Microbiology and Infectious Diseases, vol. 3, no. 4, pp. 163-168, 2013.

[21] M. Amini, "Pattern of antibiotic resistance in nosocomial infections with Gram-negative bacilli in ICU patients (Tehran, Iran) during the years 2012-2014," Journal of Basic and Clinical Pathophysiology, vol. 6, no. 1, pp. 23-30, 2018. 
[22] R. Dehbanipour, S. Rastaghi, M. Sedighi, N. Maleki, and J. Faghri, "High prevalence of multidrug-resistance uropathogenic Escherichia coli strains, Isfahan, Iran," Journal of Natural Science, Biology, and Medicine, vol. 7, no. 1, pp. 22-6, 2016.

[23] F. Davarzani, "Evaluation of antibiotic resistance pattern, alginate and biofilm production in clinical isolates of Pseudomonas aeruginosa," Iranian Journal of Public Health, vol. 50, no. 2, p. 341, 2021.

[24] E. Ghaznavi-Rad, V. Neela, M. Nor Shamsudin et al., "Diversity in the antimicrobial susceptibility patterns of methicillin-resistant Staphylococcus aureus clones," European Journal of Clinical Microbiology \& Infectious Diseases, vol. 31, no. 12, pp. 3317-3321, 2012.

[25] J.-T. Wang, S.-C. Chang, H.-Y. Wang, P.-C. Chen, Y.-R. Shiau, and T.-L. Lauderdale, "High rates of multidrug resistance in Enterococcus faecalis and E. faecium isolated from inpatients and outpatients in Taiwan," Diagnostic Microbiology and Infectious Disease, vol. 75, no. 4, pp. 406-411, 2013.

[26] R. Y. Linfield, S. Campeau, P. Injean et al., "Practical methods for effective vancomycin-resistant enterococci (VRE) surveillance: experience in a liver transplant surgical intensive care unit," Infection Control \& Hospital Epidemiology, vol. 39, no. 10, pp. 1178-1182, 2018.

[27] D. J. Anderson, R. W. Moehring, D. J. Weber et al., "Effectiveness of targeted enhanced terminal room disinfection on hospital-wide acquisition and infection with multidrug-resistant organisms and Clostridium difficile: a secondary analysis of a multicentre cluster randomised controlled trial with crossover design (BETR Disinfection)," The Lancet Infectious Diseases, vol. 18, no. 8, pp. 845-853, 2018.

[28] N. Taneja, P. Rani, R. Emmanuel, and M. Sharma, "Significance of vancomycin resistant enterococci from urinary specimens at a tertiary care centre in northern India," The Indian Journal of Medical Research, vol. 119, no. 2, pp. 72-4, 2004. 